\title{
Statins in Neurological Disorders: Mechanisms and Therapeutic Value
}

\author{
Allison B. Reiss ${ }^{1, *}$ and Elzbieta Wirkowski ${ }^{2}$ \\ ${ }^{1}$ Vascular Biology Institute and ${ }^{2}$ Division of Neurology, Department of Medicine, \\ Winthrop-University Hospital, Mineola, New York \\ E-mail: AReiss@winthrop.org; EWirkowski@winthrop.org
}

Received July 6, 2009; Revised September 21, 2009; Accepted October 20, 2009; Published November 1, 2009

\begin{abstract}
Statins are well-tolerated, mainstay drugs in cardiovascular risk management. In addition to their cholesterol-lowering properties, statins also have anti-inflammatory, vasculoprotective, and antioxidant effects. They have also been associated in some epidemiologic studies with reduced risk of Alzheimer's disease (AD), and a link between cholesterol and late-onset AD has been documented. Experimental studies in cell culture systems and animal models show that statins have neuroprotective effects that may ameliorate the damage inflicted by stroke and AD. Human studies have garnered compelling evidence that treatment with statins reduces ischemic stroke incidence independent of their lipid-lowering effects. There is also the possibility that statins and extremely low cholesterol levels may increase the risk of intracranial hemorrhage. In this review, we discuss the potential reasons for the effect of statins on stroke and $A D$, and the multiple mechanisms of action of this class of lipid-lowering drugs.
\end{abstract}

KEYWORDS: statins, stroke, Alzheimer's disease, cholesterol, amyloid beta, inflammation

\section{INTRODUCTION}

Statins, or 3-hydroxy-3-methylglutaryl-coenzyme A (HMG-CoA) reductase inhibitors, are widely prescribed as cholesterol-lowering therapy, and are considered first-line therapeutic agents for the prevention of coronary heart disease and atherosclerotic disorders related to hypercholesterolemia[1]. They are administered orally and have dose-dependent benefits in reducing plasma concentrations of cholesterol[2]. They are used for hyperlipidemia and for the primary and secondary prevention of cardiovascular (CV) disease, and clinical trials have substantiated their effectiveness in lowering mortality levels associated with $\mathrm{CV}$ disease[3,4].

Statins also have immunomodulatory, neuroprotective, and anti-inflammatory properties that are being explored for potential benefits in central nervous system disorders[5,6,7]. The etiology of a number of neurologic disorders involves both vascular dysfunction and immunopathology, and this has led to the use of statin therapy, with varying degrees of success, in neuroinflammatory and neurodegenerative processes. Statins may also be used to reduce mortality and neurological disability from stroke, and to reduce the incidence of dementia, although the latter is controversial[8,9]. 
This review summarizes the data concerning statin use in the prevention and treatment of neurological disorders. Effective treatment of these disorders, including stroke, Alzheimer's disease (AD), Parkinson's disease, and multiple sclerosis, remains a challenging task in clinical practice.

\section{PHARMACOLOGICAL PROPERTIES}

The therapeutic target organ of statins is the liver, where the drugs act on hepatocytes to inhibit endogenous cholesterol biosynthesis. This blockade results in decreased intracellular levels of cholesterol in the hepatocytes, which leads to activation of the sterol regulatory element binding protein (SREBP) pathway and compensatory up-regulation of low-density lipoprotein (LDL) receptors on the cell surface. Consequently, hepatic uptake and catabolism of LDL increases[10,11].

Six different statins (simvastatin, pravastatin, lovastatin, fluvastatin, rosuvastatin, and atorvastatin) are approved for treatment of hypercholesterolemia in humans. These statins share an HMG-like moiety and act as competitive inhibitors of HMG-CoA reductase, an enzyme of the endoplasmic reticulum that catalyzes conversion of HMG-CoA into mevalonic acid, the rate-limiting step in cholesterol biosynthesis[12] (Fig. 1). Statins bind to HMG-CoA reductase at nanomolar concentrations, leading to competitive displacement of the natural substrate, HMG-CoA, which binds at micromolar concentrations[12]. They thus prevent substrate access to active sites of the enzyme, and this results in a reduction of serum total and LDL cholesterol. Intermediate statin doses lower LDL by about 30-40\%, while high dose therapy lowers LDL by about $50 \%[13,14]$.

Statins are categorized based on criteria such as their origin, their hydrophilicity/hyrophobicity, and their specificity. Lovastatin, pravastatin, and simvastatin are all obtained by fungal fermentation, while atorvastatin, fluvastatin, rosuvastatin, and cerivastatin (withdrawn from the market in 2001) are entirely synthetic[15,16]. All statins, both fungal metabolites and synthetic compounds, confer similar coronary heart disease event reduction when adjusted for differences in lipid changes[17]. Pravastatin and rosuvastatin are hydrophilic; fluvastatin has intermediate characteristics; lovastatin, simvastatin, atorvastatin, and cerivastatin are hydrophobic[16,18]. Atorvastatin, cerivastatin, fluvastatin, rosuvastatin, and pravastatin are administered as orally active beta-hydroxy acid compounds (acid form). Lovastatin and simvastatin are administered as inactive prodrugs (lactone), which have to be enzymatically hydrolyzed to generate active forms[19]. Atorvastatin, lovastatin, simvastatin, and cerivastatin are metabolized by the cytochrome P-450 isozyme 3A4. Unlike these lipophilic statins, hydrophilic statins (such as pravastatin) are not metabolized in the liver via the cytochrome P-450 system and have little potential for adverse events through interaction with drugs metabolized via this pathway[16].

\section{CHOLESTEROL-INDEPENDENT STATIN EFFECTS}

Statins exhibit multiple nonlipid-lowering actions or "pleiotropic" effects (Table 1)[20]. These beneficial effects that extend beyond their cholesterol-lowering capacity include, among others, vasodilation, plaque stabilization, inhibition of thrombogenesis, attenuation of oxidative stress, and reduction of inflammation[21,22,23]. The anti-inflammatory effects include suppression of the release of proinflammatory cytokines, chemokines, adhesion molecules, and matrix metalloproteinases (MMPs) by inflammatory cells[24,25]. Statins can inhibit MMP-2 and MMP-9 activities by monocytes, macrophages, fibroblasts, and vascular smooth muscle cells[25]. Statins act as immunomodulators by suppressing T-cell activation and proliferation, and by reducing the expression of class II major histocompatibility complexes on antigen-presenting cells[26,27]. Antioxidant actions lead to reduced superoxide production and lipid peroxidation[28,29]. Simvastatin selectively blocks the production of free oxygen radicals generated by the stimulated macrophages[30,31]. 


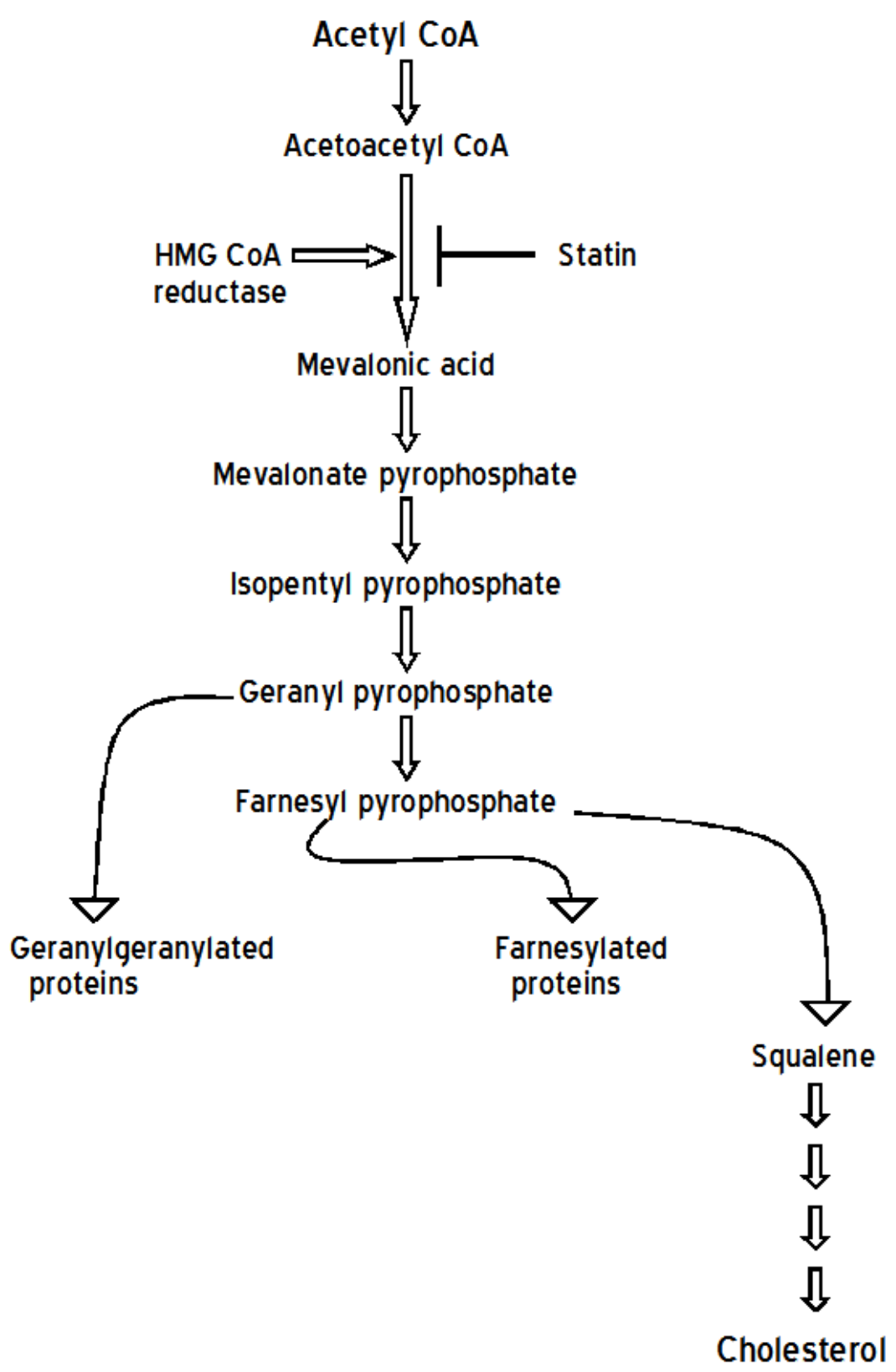

FIGURE 1. Cholesterol biosynthetic pathway. All carbon atoms in cholesterol are derived from acetyl CoA. The synthesis of mevalonic acid is catalyzed by the enzyme HMG-CoA reductase. It is the committed, rate-limiting step in cholesterol formation. This enzyme is highly regulated and the target of pharmaceutical intervention with statins. Mevalonic acid is converted to mevalonate pyrophosphate and then isopentyl pyrophosphate via ATP-requiring reactions. Six isopentyl pyrophosphates are isomerized and condensed to form squalene. The 30 -carbon linear squalene undergoes cyclization to form the four rings of the steroid nucleus, with a further series of changes to yield the 27-carbon cholesterol molecule. Alternatively, through a series of other intermediates, mevalonic acid can be converted to geranyl pyrophosphate and farnesyl pyrophosphate, metabolic products that are able to supply prenyl groups for protein prenylation. Prenylated proteins have covalently linked geranylgeranyl or farnesyl groups that anchor those proteins to membranes. Prenylation is a post-translational lipid modification that affects the function of Ras, Rho, and other small GTPases. 
TABLE 1

Pleiotropic Effects of Statins with Neuroprotective Benefits

\author{
Increasing NO bioavailability, which augments cerebral perfusion \\ Inhibition of isoprenylation of RhoA GTPase, which increases production of NO by eNOS \\ Modulation of inflammatory response with decreased production of proinflammatory cytokines \\ Inhibition of NF-kB activation, which influences inflammatory gene transcription \\ Blocking cell-surface expression of adhesion molecules \\ Decreasing susceptibility to thrombosis \\ Decreasing platelet aggregation \\ Reducing thrombin formation \\ Enhancing clot lysis \\ Stabilization of atherosclerotic plaques \\ Antioxidant effects with decreased ROS
}

\title{
The Isoprenoids and Pleiotropic Effects
}

Many of the so-called pleiotropic effects have been shown to be secondary to the inhibition of the synthesis of isoprenoid intermediates of the mevalonate pathway (Fig. 1). This important class of biomolecules, such as farnesyl pyrophosphate (FPP) and geranylgeranyl pyrophosphate (GGPP), are essential for the post-translational modification of small guanosine triphosphate (GTP)-binding proteins, such as Ras, Rac, and Rho. Ras small G-proteins are modified by either farnesylation or geranylgeranylation, whereas Rho small G-proteins are modified by geranylgeranylation. Addition of these isoprenoids to the $\mathrm{C}$ termini of small G-proteins is critical for enabling translocation and tethering of these proteins to the cell membrane, and allowing their subsequent interaction with effector molecules and cytoplasmic regulators through protein-protein and protein-lipid interactions[32,33,34]. Rho (together with its downstream target, Rho-associated coiled-coil protein kinase[ROCK]) and Rac regulate organization of cytoskeletal proteins involved in endothelial cell barrier function and are involved in inflammatory signal transduction pathways[35]. Rho participates in signaling pathways required for nuclear factor-kappa B (NF-kB) activation, leading to the induction of cytokines and chemokines[36]. Statins deplete cells of all downstream isoprenoid products, causing guanosine triphosphatase (GTPase) proteins to lose their normal membrane association and function, leading to cytosolic accumulation of these small GTPases[37,38]. In cultured human pulmonary artery endothelial cells, simvastatin inhibited the geranylgeranylation of Rac1, associated with a paradoxical increase in Rac1 GTP binding and activation[39]. The activation of Rac1 is a key step in activation of endothelial nitric oxide synthase (eNOS), responsible for production of neuroprotective nitric oxide (NO). Silencing (si)RNA-mediated Rac1 "knockdown" in endothelial cells markedly suppresses receptor signaling to eNOS[40].

Statins increase the production of vasodilators, such as NO, prostaglandin $\mathrm{I}_{2}$, and vascular endothelial growth factor, and decrease the production of vasoconstrictors, such as endothelin- 1 and angiotensin II, the terminal pressor effector hormone of the renin-angiotensin-aldosterone system. The angiotensin II octapeptide increases blood pressure by vasoconstriction and sodium and fluid retention, and acts in a pro-oxidative capacity by generating reactive oxygen species (ROS)[41]. Statins attenuate the deleterious effects of the renin-angiotensin system in several organs, not only by decreasing angiotensin II, but by down-regulating expression of the angiotensin II type 1 (AT1) receptor[42,43]. In vascular smooth muscle cells isolated from the thoracic aorta of Sprague-Dawley rats, cerivastatin reduced AT1 receptor promoter activity and decreased AT1 receptor expression in a dose-dependent fashion, and the addition of GGPP, but not FPP, was able to prevent cerivastatin-induced down-regulation of AT1 receptor expression[44]. 


\section{Statins and Nitric Oxide}

Normal endothelial function is required to maintain vascular homeostasis and is dependent on NO. NO, generated from L-arginine through the actions of the enzyme NO synthase (NOS), modulates ROS production, blood flow, platelet function, vascular permeability, and vascular tone[45,46]. NO limits inflammation and coagulation, and diminishes vascular smooth muscle cell proliferation and migration[47,48]. Statins are known to rapidly increase NO bioavailability through multiple mechanisms. This is one of the earliest effects of statin treatment[49]. NO is synthesized by three different NOS isoforms: eNOS, inducible NOS (iNOS), and neuronal NOS (nNOS).

Statins enhance iNOS expression in vascular smooth muscle cells and eNOS in endothelial cells by cholesterol-independent mechanisms involving Rho and requiring geranylgeranylation, leading to prolongation of the half-life of the NOS mRNA[50,51,52]. Statins can also rapidly induce the phosphorylation and activation of eNOS via the phosphatidylinositol-3 kinase (PI3K)/protein kinase Akt pathway. Rodents treated with statins display elevated endothelial and platelet eNOS levels, enhanced NO production, and protection against cerebral ischemia[53,54,55]. In rat vascular smooth muscle cells, atorvastatin increases expression of both iNOS and nNOS mRNA and protein via the Akt/NF-kB pathway[56]. Corroborating the rodent and cell culture studies, statin effects on platelet and endothelial eNOS have also been observed in humans[57,58]. Pravastatin treatment potentiates human platelet eNOS activity in humans[59].

Many of the pleiotropic effects of statins are neuroprotective, such as the ability to scavenge ROS and MMPs, reduce thrombogeniciity, facilitate clot lysis, up-regulate eNOS, and modulate the inflammatory response[60,61,62].

\section{IMPACT OF STATINS ON ALZHEIMER'S DISEASE}

$\mathrm{AD}$, the leading cause of dementia worldwide, is a chronic progressive condition characterized by cognitive decline and impaired memory, thinking, and behavior[63]. Morphological alterations considered as hallmarks of $\mathrm{AD}$ include amyloid plaques and neurofibrillary tangles (intracellular filamentous aggregates of the microtubule-associated protein tau), accompanied by neuroinflammation, neuronal dysfunction, and cell death. These plaques and tangles constitute potential targets for AD therapy. The 40-42 amino acid peptide, called beta-amyloid (Abeta), has been identified as a main component of amyloid plaques and is centrally implicated in the pathogenesis of AD[64]. Proteolytic processing of the amyloid precursor protein (APP) by the sequential activities of beta- and gammasecretase releases the potentially neurotoxic Abeta peptide, which is present in the brain in both its soluble and aggregated (senile plaques) forms[65]. APP can also be processed through the alpha-secretase pathway in which APP is cleaved in the middle of the Abeta region, thus precluding formation of Abeta[66].

\section{The Link Between Apolipoprotein (Apo) E and Alzheimer's Disease}

ApoE is a major apolipoprotein in the brain and is involved in lipid transport and neuronal homeostasis[67]. ApoE participates in the transport of cholesterol and other lipids in the bloodstream and in the cerebrospinal fluid (CSF), and is the most common genetic risk factor for late-onset sporadic $\mathrm{AD}[68]$. This protein is expressed by three major alleles and exists in three isoforms, apoE2, apoE3, and apoE4, which vary by single amino acid changes in their structure. Of the three forms, only the E4 allele increases the likelihood of developing $\mathrm{AD}$ and is the strongest known genetic risk factor for development of late-onset $\mathrm{AD}[69,70]$. Results from the Alzheimer's Disease Cholesterol-Lowering Treatment (ADCLT) trial suggest that statin therapy may be of particular benefit for patients with mild-to-moderate AD with the ApoE4 allele who have elevated serum cholesterol[71]. The Prospective Study of Pravastatin 
in the Elderly at Risk (PROSPER) found no such benefit[72,73]. PROSPER confirmed the association between the apoE4 allele and decline in global cognitive function, even in subjects not diagnosed with dementia. This randomized controlled trial followed a large cohort (5804 subjects aged 70-82, 50\% female) over a brief period (average 3.2 years). Half of the subjects received pravastatin, but the drug did not slow cognitive decline in any subgroup, including those with the apoE4 allele, nor did lipoprotein levels influence cognitive decline. The study did not address the effect of statins in early or mid-life age groups.

\section{Cholesterol Metabolism and Alzheimer's Disease}

The role of cholesterol metabolism in the etiopathogenesis of AD is of intense interest and is being explored in vitro, and in humans and pertinent animal models. Neurobiochemical studies have shown that the lipid environment modulates APP processing[74]. Membrane cholesterol promotes amyloid production through processing of the type I transmembrane protein APP by the integral membrane proteins beta- and gamma-secretase, and can therefore increase generation of toxic beta-amyloidogenic peptides. Beta-secretase activity is thought to occur primarily in lipid rafts, which are detergent-insoluble microdomains rich in cholesterol and sphingomyelin[75]. Reduction in cholesterol concentration decreases beta-secretase activity[76]. Depletion of membrane cholesterol from buoyant membrane microdomains derived from cultured cells with methyl-beta-cyclodextrin completely inhibits gammasecretase cleavage activity, which can then be restored by cholesterol replenishment[77]. The effects of cholesterol depletion on these secretases are independent of each other[78]. Upon membrane cholesterol depletion by either pharmacological or biochemical means, alpha-secretase activity is enhanced and Abeta production diminished[79,80]. Thus, cholesterol levels may influence the balance between amyloidogenic and amyloidolytic (nonamyloidogenic) proteolytic processing of APP[75].

In cells in culture, reducing cholesterol levels with statins causes a marked reduction in Abeta[76,81]. Statins can affect both beta- and gamma-secretase activities, thereby decreasing the breakdown of APP, and it has been proposed that this may lead to reduction in the risk of $\mathrm{AD}[76,82]$. Amyloidogenesis under conditions of cholesterol reduction may also be averted due to statin-induced up-regulation of alphasecretase[80,83]. Gellermann and colleagues[84] found that lovastatin reduced the formation of amyloidlike Abeta plaques by cultured primary human macrophages by $35 \%$. Microglia mount a robust phagocytic response to Abeta, but when exposed to statins, they exhibit reduced phagocytosis with Abeta stimulation and this effect occurs via depletion of isoprenoid precursors[85].

In murine studies, diet-induced hypercholesterolemia increases Abeta accumulation and accelerates AD-related pathology[86,87]. Similarly, in New Zealand White rabbits, a cholesterol-enriched diet increased intraneuronal Abeta immunoreactivity. Upon removal of cholesterol from the diet of these animals, a reduction in brain Abeta levels was observed along with activation of microglia[88].

Several murine studies show a salutary effect of statins on amyloid deposition[81,89]. Other studies have shown no benefit or added amyloid burden[90,91]. In transgenic mice overexpressing human APP, lovastatin or pravastatin treatment both induced dose-dependent reductions in total Abeta peptides[92]. In a transgenic mouse model of taupathy, atorvastatin and simvastatin were both effective in reducing neurofibrillary tangle burden[93].

$\mathrm{Li}$ and colleagues[90] evaluated female mice that overexpress the human APP with a Swedish double mutation ( $\mathrm{Tg} 2576$ mice) for behavior and cerebral amyloidosis. They compared $\mathrm{Tg} 2576$ mice treated with $50 \mathrm{mg}$ simvastatin per kilogram body weight per day for 3 months to mice not receiving the drug, and found reversal of spatial learning and memory deficits in treated mice. Despite improved cognitive function, the simvastatin-treated $\mathrm{Tg} 2576$ mice failed to show a significant decrease in brain Abeta level. When male and female Tg2576 mice were given lovastatin (100 mg/kg/day for 3 weeks), Park et al.[91] found that the response differed by gender with increased Abeta production and plaque deposition in female, but not in male mice. The overall effect of statins on Abeta in mice has not been resolved. 
The association between cholesterol and cognition is complicated and the efficacy of statins at slowing the progression of $\mathrm{AD}$ remains controversial. A number of epidemiological studies have demonstrated that chronically elevated serum total cholesterol is a risk factor for developing AD later in life $[94,95,96]$. Launer and colleagues found that low mid-life total cholesterol was associated with fewer numbers of dendritic plaques and tangles[97]. In a postmortem study of 100 individuals, Kuo et al. observed significantly higher LDL and significantly lower HDL in the documented AD cases vs. controls[98]. In contrast, a number of other studies, including the Framingham study, have failed to detect an association between raised total cholesterol and $\mathrm{AD}[99,100]$. Overall, whether hypercholesterolemia is a clinical risk factor for $\mathrm{AD}$ is still unresolved.

\section{Statins in Alzheimer's Disease: The Human Studies}

Past findings with respect to reduction in AD risk with statin use have been inconsistent[101]. However, several recent prospective studies have reported that statin use lowers AD incidence. Results from the Sacramento Area Latino Study on Aging (SALSA), a prospective cohort observational study of older ( $\geq 60$ years of age) Mexican Americans from the Sacramento, CA area, indicate that in this population, statin use was associated with a significant reduction in the incidence of combined dementia and cognitive impairment without dementia (CIND). Over a 5-year period, rates of dementia/CIND were $44 \%$ lower in statin users[9]. In the Rotterdam Study, a large clinical prospective study, Haag and colleagues[102] found that over an average 9.2 years of follow-up of persons with an average age of 69.4 at baseline, statin treatment reduced the risk of incident AD regardless of apoE genotype, and the protective effect of statins was shown to be independent of their lipophilicity. Nonstatin cholesterol-lowering drugs (fibrates, bile-acid binding resins, or nicotinic acid and derivatives) failed to provide protection. In the Alzheimer's Disease Anti-inflammatory Prevention Trial (ADAPT) study, a prospective observational study of elective statin use in an at-risk-for-AD population of elderly individuals, statin use was associated with significantly reduced risk of incident AD after adjustment for confounding variables[103].

Any protective actions of statins may be a direct consequence of reducing cholesterol levels and may also be independent of cholesterol lowering[104]. Small doses of statins below the threshold for impacting cholesterol levels can block isoprenoid synthesis in neuroblastoma cells, interfering with APP trafficking and inhibiting amyloidogenic APP processing[105]. In cultured hippocampal neurons, lovastatin inhibited APP endocytosis in a GGPP-dependent manner, causing decreased generation of Abeta[106]. Addition of GGPP to APP overexpressing cells treated with lovastatin fully reverses the lovastatin-mediated reduction in Abeta[107]. On the whole, accumulated evidence in cell culture experiments indicates that statins attenuate the amyloidogenic process by inhibiting both cholesterol and isoprenoid biosynthesis[108,109].

Despite some biochemical rationale for statin effectiveness in $\mathrm{AD}$ and the positive results obtained in SALSA, ADAPT, and the Rotterdam Study, conflicting data continue to be revealed. Two double-blind, randomized, placebo-controlled trials of statins (PROSPER, which was previously mentioned, and the Heart Protection Study [HPS]) were analyzed and neither showed any impact of statins on cognitive function[73,110]. PROSPER included 5804 patients ranging in age from 70 to 82 years with mean follow-up of 3.2 years, and the HPS was comprised of 20,536 patients with 5806 patients age 70 years or above at study entry and mean follow-up of 5 years. PROSPER patients received pravastatin or placebo, while HPS patients received simvastatin or placebo. In the Religious Orders Study, a prospective clinicalpathologic study of dementia in older (74.9 year average age at baseline) Catholic clergy from across the U.S. without signs of dementia at baseline, no relationship was found between statin use and incidence of $\mathrm{AD}$ [111]. Despite a 12-year follow-up, no effect of statins was found on AD or cognition, and no relation of statins to tangles or amyloid load.

Results are also starting to emerge from both the Lipitor's Effect in Alzheimer's Dementia (LEADe) Study and the Cholesterol Lowering Agent to Slow Progression of AD (CLASP) study[112,113]. LEADe is an 80-week, international, multicenter, randomized, double-blind, placebo-controlled study of 
atorvastatin $80 \mathrm{mg}$ daily vs. placebo in patients age 50-90 years (mean age 74 years) with mild-tomoderate $\mathrm{AD}$ receiving background therapy of donepezil $10 \mathrm{mg}$ daily. In total, 641 subjects were enrolled and, thus far, there has been a lack of significance of the positive signal of benefit on the Alzheimer's Disease Assessment Scale-cognitive subscale (ADAS-cog, a scale widely used as an efficacy measure in clinical drug trials of $\mathrm{AD}$ ) in the treatment of $\mathrm{AD}$ with atorvastatin[114]. It has also been reported in the LEADe study that in posthoc analysis of the subset of individuals evaluated for APOE genotype, atorvastatin produced a significantly reduced decline on the ADAS-cog compared with placebo. The difference was not related to gender, nor to apoE4 allele status, and may have been due to differences in the genotyped vs. nongenotyped study populations[115].

The CLASP study, another large, multicenter, randomized, double-blind, placebo-controlled trial, was designed to investigate the effects of an 18-month simvastatin treatment (20 mg daily for 6 weeks, then 40 $\mathrm{mg}$ daily for the remainder of the study period) vs. placebo. A total of 406 subjects with mild-to-moderate AD (mean age of 74 years) were randomized and detailed results are awaited. Preliminary results did not indicate a benefit of simvastatin in AD treatment[113,116].

\section{CEREBROVASCULAR DISORDERS AND STATINS}

There are a number of issues that require clarification: Does cholesterol level contribute to ischemic or hemorrhagic brain pathology? Do statins contribute to decreasing the pathology and, if so, by what mechanism? Do statins serve as primary vs. secondary prevention and what is their therapeutic role in the acute phase of stroke?

In general, the role of statins is more complicated than just lowering cholesterol. As previously discussed, pleiotrophic actions of statins include antithrombotic effects via inactivation of prothrombin and antiplatelet effects through thromboxane A2 reduction[117,118,119]. Statins also reduce blood viscosity and red blood cell aggregation[120,121].

In contrast to coronary artery disease, brain atherosclerotic disease can manifest as ischemia or hemorrhage. Strokes occur in the population on average in persons 10 years older than patients experiencing myocardial infarction. Complications of cerebrovascular disorders depend heavily on additional risk factors like hypertension, diabetes, smoking, or alcohol use[122].

Cerebral infarction is not a uniform entity. Stroke is a heterogeneous disorder with various underlying pathophysiology. Endothelial dysfunction with thickening of the endothelium of the small "end artery" of the brain is thought to play an important role in the pathogenesis of lacunar stroke[123,124]. Hypertension and diabetes mellitus are the primary risk factors for this type of stroke, which accounts for one-quarter of cerebral infarctions[125]. Atherosclerosis, responsible for myocardial infarction, stroke, and peripheral vascular disease, affects large- and medium-sized arteries. Atherosclerosis may be detected in arteries supplying the brain: the internal carotid artery, middle cerebral artery, and basilar artery[126]. Atherothrombotic stroke occurs as a result of atherosclerosis progression and presents with a frequently devastating clinical picture. Embolic stroke is usually cardiogenic in its etiology. Hemorrhagic stroke consists of intracerebral, subdural, and subarachnoid type[127].

\section{Role of Cholesterol in Ischemic and Hemorrhagic Stroke}

Lacunar infarcts and hypertensive intracerebral hemorrhage occur in the same brain topographic location, within deep structures in the vascular distribution of the small perforating intracerebral arteries, including the putamen, thalamus, and pons. This suggests a similar pathophysiological process related to chronic hypertensive damage[128,129]. The Northern Manhattan Study (NOMAS) is a prospective, populationbased incidence and case follow-up study designed to determine stroke incidence, risk factors, and outcomes in a multiethnic, urban population in a well-defined area of Manhattan. One of many questions that NOMAS attempted to answer was: Who gets lacunar infarct vs. intracranial hypertensive hemorrhage and why? Between July 1, 1993 and November 1, 1996, NOMAS identified 151 cases of lacunar infarct 
and 83 cases of deep intracerebral hemorrhage. Total cholesterol level data were available for $74 \%$ of the lacunar infarct cases and $84 \%$ of the deep intracerebral hemorrhage cases. The study found that a history of hypertension was prevalent in both lacunar infarct (86\%) and deep intracerebral hemorrhage (77\%) patients, but hypercholesterolemia occurred mostly in lacunar ischemic strokes, while hypocholesterolemia was more prevalent in cerebral hemorrhage[130]. In this study, risk factor data were collected by chart review and although total cholesterol was measured within 1 day of hospital admission, the stroke subtype itself may have influenced cholesterol level.

The increased risk of all ischemic strokes associated with higher total cholesterol as well as lack of this association has been reported in many studies[131,132]. In the Women's Health Study, a prospective cohort study of 27,937 apparently healthy women, all registered health professionals throughout the U.S. and the Commonwealth of Puerto Rico aged 45 years and above (mean age 54.7), a strong association was noted between the risk of ischemic stroke and both total cholesterol $(p<0.001)$ and LDL cholesterol levels $(p<0.003)$ over 11 years of follow-up and after adjustment for a large number of potential confounders[133]. In this large study, $94.5 \%$ of the women were white, $1.8 \%$ were black, and $3.7 \%$ were of other ethnicity. Stroke was self-reported and confirmed by review of medical records. Intraindividual variability was not accounted for since lipid levels were measured only once, at inception. Tirschwell et al. analyzed data from two ongoing case control studies of myocardial infarction and stroke. Ischemic stroke, hemorrhagic stroke, and subarachnoid hemorrhage were analyzed. The study found an association between higher total cholesterol levels and increased risk of ischemic stroke, especially lacunar and atherothrombotic subtypes, in younger patients (age below 66 years) or patients with HDL $<50 \mathrm{mg} / \mathrm{dl}$. The lowest levels of total cholesterol contributed to increased risk of the hemorrhagic stroke subtype[134].

A number of studies have documented a decreased risk of ischemic stroke in patients with higher HDL[135,136]. In a NOMAS study of the elderly (67\% of cases and $69 \%$ of controls were aged 65 years or older), 539 ischemic stroke cases were matched by age, sex, and race/ethnicity to 905 controls. The ischemic stroke patients were 55\% women, 53\% Hispanic, 28\% black, and 19\% white. In this NOMAS population, the HDL cholesterol and stroke association noted in all three racial/ethnic groups persisted after adjustment for multiple potential confounders, and was found to be especially important in largevessel atherosclerotic strokes and was seen in nonatherosclerotic infarction. In this study, no relationship was found between total cholesterol levels and stroke risk[137].

The Framingham study, a prospective study in an overwhelmingly white cohort residing in the town of Framingham, MA, found no connection between cholesterol level and stroke[138]. In the same study, high cholesterol level was associated with elevated inflammatory protein in the serum. In EUROSTROKE, a collaborative prospective case control study of European populations, total cholesterol was not associated with any significant increase in stroke risk[139]. In another study, Emond and Zareba looked at 2873 women of different ages participating in the Framingham Study, and found that in younger women (age 55 or below) with stroke, mortality was associated with hypercholesterolemia, while in an older population, the trend was reversed[140]. One may question the influence of metabolic syndrome in younger, hypercholesterolemic women with stroke. Metabolic syndrome is associated with increased mortality and incidence of ischemic stroke[141]. In the Multiple Risk Factor Intervention Trial (MR FIT), over 350,000 men were screened for multiple stroke risk factors and it was found that a serum cholesterol level under $4.14 \mathrm{mmol} / \mathrm{l}$ increased the risk of fatal intracranial hemorrhage, while a cholesterol level above $7.23 \mathrm{mmol} / \mathrm{l}$ increased the risk of death from cerebral ischemia[142]. A very interesting study from Japan[143] suggested that in a population where animal product intake is half of that in Western populations, consumption of animal fat and cholesterol resulted in reduced risk of mortality from cerebral infarction. This is an example of a population that traditionally does not enter statin studies.

The association between low total cholesterol and risk of hemorrhage is confusing. The Tirschwell study[134] showed that the subgroup of patients with the lowest level of total cholesterol had an increased risk of hemorrhagic stroke. The MR FIT study, which included exclusively men, suggested an association between low cholesterol and intracerebral hemorrhage, but not subarachnoid hemorrhage[142]. The association had significance in hypertensive, but not amyloidal, bleeds. Gender differences have been 
found in some studies, including a cohort of persons enrolled in the Northern California Kaiser Permanente Medical Care Program from 1978 through 1993[144]. An evaluation of 71,843 persons aged 40-89 years in this ethnically diverse population showed a statistically increased risk for intracerebral hemorrhage only in males over age 65 with low levels of serum cholesterol. However, there were very few women with low cholesterol levels in this population. In a Swedish study of 54,000 men and women, relative risk for subarachnoid hemorrhage increased with decreasing serum cholesterol level in men and for intracerebral hemorrhage in women, but not for subarachnoid hemorrhage in women[145]. The biological explanation for a possible association between low cholesterol and intracerebral hemorrhage is difficult, but low cholesterol can contribute to arterial media layer smooth muscle cell necrosis, weakening the vessel wall[142].

\section{Neuroprotective Role of Statins in Stroke}

Another important issue to address is a neuroprotective role of statins as primary prevention. In a retrospective analysis of the NOMAS study, 650 patients age 40 and older with first ischemic stroke were interviewed regarding medication taken at home prior to the event. Patients taking lipid-lowering agents ( $8.8 \%$ of the patients, with $90.9 \%$ of these taking statins) at the time of stroke had a lower poststroke mortality at 90 days and a lower risk of worsening during hospitalization. However, there was no difference in outcomes at 6 months[146]. Similarly, in a large prospective study from Vienna, a significant decrease in severity of stroke-induced deficits at 1 week was observed among patients who were taking statins at the time of their stroke[147]. The effect is likely due to anti-inflammatory mechanisms as well as up-regulation of eNOS. To support this hypothesis, patients hospitalized with infections (pneumonia, urinary tract infection, and cellulitis) had decreased rates of sepsis if they were taking statins at the time of infection[148]. In patients with acute ischemic stroke in Barcelona, Spain, premorbid statin use gave no significant benefit in the short term, but was associated with better functional outcome[149].

Can statins exert a neuroprotective effect during the acute phase of a cerebral bleed? The injury during acute brain hemorrhage occurs not only through mechanical destruction due to mass effect, but mainly due to local inflammation and apoptosis[150]. Anti-inflammatory propensities of statins can improve outcome in acute bleed. Atorvastatin administration to rats with collagenase-induced deep intracerebral hemorrhage resulted in reduced edema, perihematomal cell death, decreased filtration of leukocytes and microglia, and increased eNOS expression. The functional outcome in this rodent model was improved as well[151]. Neuroprotective effects of statins were absent in eNOS-deficient mice[152], therefore suggesting that enhancement of eNOS activity by statins is one of the main neuroprotective mechanisms. In addition, statins cause a dose-dependent inhibition of leukocyte recruitment and migration into the central nervous system by suppressing adhesion molecules as well as proinflammatory mediators, such as TNF-alpha and iNOS[153]. In summary, attenuation of inflammatory response, decreasing brain edema, and improving local cerebral blood flow can positively affect outcomes after intracerebral hemorrhage.

\section{Statins and Brain Hemorrhage}

The impact of statin use and low cholesterol (especially LDL cholesterol) levels on the incidence of primary intracranial hemorrhage is still under debate. Low cholesterol is known to be associated with increased cerebral hemorrhage. In the Stroke Prevention by Aggressive Reduction in Cholesterol Levels (SPARCL) trial in which high-dose atorvastatin for secondary stroke prevention was analyzed, a significant increase of brain hemorrhages in the treatment group was observed, whereas total and LDL cholesterol levels did not affect the risk of hemorrhagic stroke[154]. Interestingly, some of the randomized trials of cholesterol lowering with statins have not shown increased risk of brain hemorrhage. In a large meta-analysis with more than 90,000 patients treated with statins for primary and secondary prevention of stroke, the frequency of brain hemorrhage was not increased[155]. The National Acute 
Stroke Israeli Surveys (NASIS) looked at outcome in 312 intracerebral hemorrhage subjects with mean age of $77.4 \pm 9.9$ years, 89 of them receiving statins at the time of their event (hemorrhagic transformation of ischemic strokes was excluded), and found that statin-treated patients had lower neurological disability at onset, lower death and dependency rates, and increased chances for a positive outcome[156]. In a pooled analysis of three large, placebo-controlled, randomized trials, pravastatin was found to reduce total stroke incidence across a wide range of patient characteristics and manifested as a $24 \%$ reduction in nonfatal nonhemorrhagic strokes, but with no evidence that pravastatin had an effect on hemorrhagic strokes. It is important to realize that patients with baseline normal cholesterol level might not have been included in the study[157]. Low levels of LDL cholesterol, and possibly total cholesterol, have been associated with greater risk of hemorrhagic transformation after acute ischemic stroke attributable to large artery atherothrombosis, but not in cardioembolism[158].

The interaction between apoE and statin use was looked at by Woo and colleagues[159]. They found that treatment with statins did not increase risk for intracerebral hemorrhage. History of hypercholesterolemia was associated with decreased risk of intracerebral hemorrhage. Use of statins was statistically the same in the hypercholesterolemia group with intracerebral hemorrhage as in controls (hypercholesterolemia without intracerebral hemorrhage). There was no different effect of statins on lobar vs. nonlobar bleed. Risk of intracerebral hemorrhage was significantly lower in the hypercholesterolemic group with statin use and apoE3 genotype.

Some studies suggested that the apoE genotype can determine responsiveness to statins. Patients with the apoE2 genotype may lower their cholesterol more effectively with statins than patients with apoE4[160].

Feigin et al.[161] found that hypercholesterolemia was associated with a reduced risk of subarachnoid hemorrhage. On the other hand, use of statins reduces risk of cerebral vasospasm. In a systematic review of nine longitudinal studies and 11 case control studies, Teunissen and colleagues found no effect of hypercholesterolemia on risk of subarachnoid hemorrhage in either males or females[162].

Hemorrhagic transformation of ischemic stroke occurs in $6.8 \%$ of patients treated with the thrombolytic agent intravenous tissue plasminogen activator (tPA), 10-12\% of patients treated with intrarterial tPA, and 7-8\% of patients treated with MERCI (mechanical embolus removal in cerebral ischemia) clot retrieval. Mild hemorrhagic transformation is clinically silent, but large ones can affect outcome. Although statins are recommended in ischemic stroke, patients with lower LDL cholesterol had more hemorrhagic transformation regardless of statin used or type of intervention[163].

The SPARCL study showed that use of high-dose atorvastatin $(80 \mathrm{mg} /$ day $)$ increased the relative risk of hemorrhage by 66\%[154]. Does low cholesterol trigger intracerebral hemorrhage or is it an epiphenomenon? Studies of statin use in coronary artery disease have not demonstrated an increase in intracerebral hemorrhages, but the population was 10 years younger than the typical stroke population. It is possible that other effects of statins, such as reduction of thromboxane A2 and thrombin formation, as well as reduced blood viscosity, could be contributing factors.

Multiple epidemiological studies examining statins and stroke are described herein. These studies involve numerous different types of cohorts with respect to gender, ethnicity, socioeconomic status, age, and geographic location. Thus, data from these studies could be confounded by demographics and cultural and lifestyle factors that are particular to each cohort, but are not addressed in the study. The specific populations are described briefly here, but this is an overview. For more detail and to assess study strength, it is advisable to consult the actual source material cited in the reference list.

\section{CONCLUSIONS}

In summary, exploration of the use of statins in the treatment of stroke and $\mathrm{AD}$ is rapidly evolving. There are a lot of data to support the use of these agents in those with prior cerebrovascular disease and as pretreatment for ischemic stroke[164]. The use of statins in the acute phase of stroke for its brainprotective effect is under study, along with many other potential approaches[165]. In patients who were 
taking a statin at the time of acute ischemic stroke, withdrawal of the statin is not advisable and may worsen outcome[166].

Although observational studies have been promising, the use of statins for primary prevention of AD is not supported by clinical findings at this time[110].

\section{ACKNOWLEDGMENTS}

This work was supported by a grant from the Neuroscience Education and Research Foundation and an Innovative Research Grant from the Arthritis Foundation (Reiss). We would like to thank Dr. Amy Glass for composing Fig. 1.

\section{REFERENCES}

1. Vaughan, C.J., Gotto, A.M., Jr., and Basson, C.T. (2000) The evolving role of statins in the management of atherosclerosis. J. Am. Coll. Cardiol. 35, 1-10.

2. Law, M.R., Wald, N.J., and Rudnicka, A.R. (2003) Quantifying effect of statins on low density lipoprotein cholesterol, ischaemic heart disease, and stroke: systematic review and meta-analysis. BMJ 326, 1423.

3. LaRosa, J.C., He, J., and Vupputuri, S. (1999) Effect of statins on risk of coronary disease: a meta-analysis of randomized controlled trials. JAMA 282, 2340-2346.

4. Schwartz, G.G., Olsson, A.G., Ezekowitz, M.D., Ganz, P., Oliver, M.F., Waters, D., Zeiher, A., Chaitman, B.R., Leslie, S., and Stern, T. (2001) Effects of atorvastatin on early recurrent ischemic events in acute coronary syndromes: the MIRACL study: a randomized controlled trial. JAMA 285, 1711-1718.

5. Johnson-Anuna, L.N., Eckert, G.P., Franke, C., Igbavboa, U., Muller, W.E., and Wood, W.G. (2007) Simvastatin protects neurons from cytotoxicity by up-regulating Bcl-2 mRNA and protein. J. Neurochem. 101, 77-86.

6. Zacco, A., Togo, J., Spence, K., Ellis, A., Lloyd, D., Furlong, S., and Piser, T. (2003) 3-Hydroxy-3-methylglutaryl coenzyme A reductase inhibitors protect cortical neurons from excitotoxicity. J. Neurosci. 23, 11104-11111.

7. Halcox, J.P. and Deanfield, J.E. (2004) Beyond the laboratory: clinical implications for statin pleiotropy. Circulation 109, II42-II48.

8. Li, G., Larson, E.B., Sonnen, J.A., Shofer, J.B., Petrie, E.C., Schantz, A., Peskind, E.R., Raskind, M.A., Breitner, J.C., and Montine, T.J. (2007) Statin therapy is associated with reduced neuropathologic changes of Alzheimer disease. Neurology 69, 878-885.

9. Cramer, C., Haan, M.N., Galea, S., Langa, K.M., and Kalbfleisch, J.D. (2008) Use of statins and incidence of dementia and cognitive impairment without dementia in a cohort study. Neurology 71, 344-350.

10. Brown, M.S. and Goldstein, J.L. (1997) The SREBP pathway: regulation of cholesterol metabolism by proteolysis of a membrane-bound transcription factor. Cell 89, 331-340.

11. Brown, M.S. and Goldstein, J.L. (1999) A proteolytic pathway that controls the cholesterol content of membranes, cells, and blood. Proc. Natl. Acad. Sci. U. S. A. 96, 11041-11048.

12. Istvan, E.S. and Deisenhofer, J. (2001) Structural mechanism for statin inhibition of HMG-CoA reductase. Science 292, 1160-1164.

13. Andrews, T.C., Ballantyne, C.M., Hsia, J.A., and Kramer, J.H. (2001) Achieving and maintaining National Cholesterol Education Program low-density lipoprotein cholesterol goals with five statins. Am. J. Med. 111, $185-191$.

14. Anon. (1994) Randomised trial of cholesterol lowering in 4444 patients with coronary heart disease: the Scandinavian Simvastatin Survival Study (4s). Lancet 344, 1383-1389.

15. Manzoni, M. and Rollini, M. (2002) Biosynthesis and biotechnological production of statins by filamentous fungi and application of these cholesterol-lowering drugs. Appl. Microbiol. Biotechnol. 58, 555-564.

16. Schachter, M. (2005) Chemical, pharmacokinetic and pharmacodynamic properties of statins: an update. Fundam. Clin. Pharmacol. 19, 117-125.

17. Goldenberg, N. and Glueck, C. (2009) Efficacy, effectiveness and real life goal attainment of statins in managing cardiovascular risk. Vasc. Health Risk Manag. 5, 369-376.

18. Corsini, A., Bellosta, S., Baetta, R., Fumagalli, R., Paoletti, R., and Bernini, F. (1999) New insights into the pharmacodynamic and pharmacokinetic properties of statins. Pharmacol. Ther. 84, 413-428.

19. Caron, G., Ermondi, G., and Testa, B. (2007) Predicting the oxidative metabolism of statins: an application of the MetaSite algorithm. Pharm. Res. 24, 480-501.

20. Bonetti, P.O., Lerman, L.O., Napoli, C., and Lerman, A. (2003) Statin effects beyond lipid-lowering-are they clinically relevant? Eur. Heart J. 24, 225-248.

21. Liao, J.K. (2005) Effects of statins on 3-hydroxy-3-methylglutaryl coenzyme a reductase inhibition beyond lowdensity lipoprotein cholesterol. Am. J. Cardiol. 96, 24F-33F. 
22. Dangas, G., Badimon, J.J., Smith, D.A., Unger, A.H., Levine, D., Shao, J.H., Meraj, P., Fier, C., Fallon, J.T., and Ambrose, J.A. (1999) Pravastatin therapy in hyperlipidemia: effects on thrombus formation and the systemic hemostatic profile. J. Am. Coll. Cardiol. 33, 1294-1304.

23. Rikitake, Y., Kawashima, S., Takeshita, S., Yamashita, T., Azumi, H., Yasuhara, M., Nishi, H., Inoue, N., and Yokoyama, M. (2001) Anti-oxidative properties of fluvastatin, an HMG-CoA reductase inhibitor, contribute to prevention of atherosclerosis in cholesterol-fed rabbits. Atherosclerosis 154, 87-96.

24. Rosenson, R.S., Tangney, C.C., and Casey, L.C. (1999) Inhibition of proinflammatory cytokine production by pravastatin. Lancet 353, 983-984.

25. Nagashima, H., Aoka, Y., Sakomura, Y., Sakuta, A., Aomi, S., Ishizuka, N., Hagiwara, N., Kawana, M., and Kasanuki, H. (2002) A 3-hydroxy-3-methylglutaryl coenzyme A reductase inhibitor, cerivastatin, suppresses production of matrix metalloproteinase-9 in human abdominal aortic aneurysm wall. J. Vasc. Surg. 36, $158-163$.

26. Arnaud, C., Veillard, N.R., and Mach, F. (2005) Cholesterol-independent effects of statins in inflammation, immunomodulation and atherosclerosis. Curr. Drug Targets 5, 127-134.

27. Ghittoni, R., Patrussi, L., Pirozzi, K., Pellegrini, M., Lazzerini, P.E., Capecchi, P.L., Pasini, F.L., and Baldari, C.T. (2005) Simvastatin inhibits T-cell activation by selectively impairing the function of Ras superfamily GTPases. FASEB J. 19, 605-607.

28. Ajith, T.A., Riji, T., and Anu, V. (2008) In vitro anti-oxidant and DNA protective effects of the novel 3-hydroxy-3methylglutaryl coenzyme A reductase inhibitor rosuvastatin. Clin. Exp. Pharmacol. Physiol. 35, 625-629.

29. Hussein, O., Schlezinger, S., and Rosenblat, M. (1997) Reduced susceptibility of LDL to lipid peroxidation after fluvastatin therapy is associated with the hypocholesterolemic effect of the drug and its binding to the LDL. Atherosclerosis 128, 11-18.

30. Giroux, L.M., Davignon, J., and Naruszewicz, M. (1993) Simvastatin inhibits the oxidation of low-density lipoproteins by activated human monocyte derived macrophages. Biochim. Biophys. Acta 1165, 335-338.

31. Girona, J., La Ville, A.E., and Sola, R. (1999) Simvastatin decreases aldehyde production derived from lipoprotein oxidation. Am. J. Cardiol. 83, 846-851. Goldstein, J.L. and Brown, M.S. (1990) Regulation of the mevalonate pathway. Nature 343, 425-430.

33. Zhang, F.L. and Casey, P.J. (1996) Protein prenylation: molecular mechanisms and functional consequences. Annu. Rev. Biochem. 65, 241-269.

34. Konstantinopoulos, P.A., Karamouzis, M.V., and Papavassiliou, A.G. (2007) Post-translational modifications and regulation of the RAS superfamily of GTPases as anticancer targets. Nat. Rev. Drug Discov. 6, 541-555.

35. Chen, W., Pendyala, S., Natarajan, V., Garcia, J.G., and Jacobson, J.R. (2008) Endothelial cell barrier protection by simvastatin: GTPase regulation and NADPH oxidase inhibition. Am. J. Physiol. Lung Cell. Mol. Physiol. 295, L575L583.

36. Montaner, S., Perona, R., Saniger, L., and Lacal, J.C. (1998) Multiple signalling pathways lead to the activation of the nuclear factor kappaB by the Rho family of GTPases. J. Biol. Chem. 273, 12779-12785.

37. Cordle, A., Koenigsknecht-Talboo, J., Wilkinson, B., Limpert, A., and Landreth, G. (2005) Mechanisms of statinmediated inhibition of small G-protein function. J. Biol. Chem. 280, 34202-34209.

38. Zipp, F., Waiczies, S., Aktas, O., Neuhaus, O., Hemmer, B., Schraven, B., Nitsch, R., and Hartung, H.P. (2007) Impact of HMG-CoA reductase inhibition on brain pathology. Trends Pharmacol. Sci. 28, 342-349.

39. Jacobson, J.R., Dudek, S.M., Birukov, K.G., Ye, S.Q., Grigoryev, D.N., Girgis, R.E., and Garcia, J.G. (2004) Cytoskeletal activation and altered gene expression in endothelial barrier regulation by simvastatin. Am. J. Respir. Cell Mol. Biol. 30, 662-670.

40. Kou, R. and Michel, T. (2007) Epinephrine regulation of the endothelial nitric-oxide synthase: roles of RAC1 and beta3-adrenergic receptors in endothelial NO signaling. J. Biol. Chem. 282, 32719-32729.

41. Bayorh, M.A., Ganafa, A.A., Eatman, D., Walton, M., and Feuerstein, G.Z. (2005) Simvastatin and losartan enhance nitric oxide and reduce oxidative stress in salt-induced hypertension. Am. J. Hypertens. 18, 1496-1502.

42. Park, J.K., Muller, D.N., Mervaala, E.M., Dechend, R., Fiebeler, A., Schmidt, F., Bieringer, M., Schafer, O., Lindschau, C., Schneider, W., Ganten, D., Luft, F.C., and Haller, H. (2000) Cerivastatin prevents angiotensin IIinduced renal injury independent of blood pressure- and cholesterol-lowering effects. Kidney Int. 58, 1420-1430.

43. Wassmann, S., Laufs, U., Baumer, A.T., Muller, K., Konkol, C., Sauer, H., Bohm, M., and Nickenig, G. (2001) Inhibition of geranylgeranylation reduces angiotensin II-mediated free radical production in vascular smooth muscle cells: involvement of angiotensin AT1 receptor expression and Rac1 GTPase. Mol. Pharmacol. 59, 646-654.

44. Ichiki, T., Takeda, K., Tokunou, T., Iino, N., Egashira, K., Shimokawa, H., Hirano, K., Kanaide, H., and Takeshita, A. (2001) Downregulation of angiotensin II type 1 receptor by hydrophobic 3-hydroxy-3-methylglutaryl coenzyme A reductase inhibitors in vascular smooth muscle cells. Arterioscler. Thromb. Vasc. Biol. 21, 1896-1901.

45. Moncada, S. and Higgs, E.A. (2006) Nitric oxide and the vascular endothelium. Handb. Exp. Pharmacol. 176, 213254.

46. Tziros, C. and Freedman, J.E. (2006) The many antithrombotic actions of nitric oxide. Curr. Drug Targets 7, 12431251.

47. Cirino, G., Fiorucci, S., and Sessa, W.C. (2003) Endothelial nitric oxide synthase: the Cinderella of inflammation? Trends Pharmacol. Sci. 24, 91-95. 
48. Grisham, M.B., Jourd'Heuil, D., and Wink, D.A. (1999) Nitric oxide. I. Physiological .chemistry of nitric oxide and its metabolites: implications in inflammation. Am. J. Physiol. Gastrointest. Liver Physiol. 276, G315-G321.

49. John, S., Delles, C., Jacobi, J., Schlaich, M.P., Schneider, M., Schmitz, G., and Schmieder, R.E. (2001) Rapid improvement of nitric oxide bioavailability after lipid-lowering therapy with cerivastatin within two weeks. $J$. Am. Coll. Cardiol. 37, 1351-1358.

50. Kolyada, A.Y., Fedtsov, A., and Madias, N.E. (2001) 3-Hydroxy-3-methylglutaryl coenzyme A reductase inhibitors upregulate inducible NO synthase expression and activity in vascular smooth muscle cells. Hypertension 38, $1024-1029$.

51. Chen, H., Ikeda, U., Shimpo, M., Ikeda, M., Minota, S., and Shimada, K. (2000) Fluvastatin upregulates inducible nitric oxide synthase expression in cytokine-stimulated vascular smooth muscle cells. Hypertension 36, 923-928.

52. Rikitake, Y. and Liao, J.K. (2005) Rho GTPases, statins, and nitric oxide. Circ. Res. 97, 1232-1235.

53. Endres, M., Laufs, U., Huang, Z., Nakamura, T., Huang, P., Moskowitz, M.A., and Liao, J.K. (1998) Stroke protection by 3-hydroxy-3-methylglutaryl (HMG)-CoA reductase inhibitors mediated by endothelial nitric oxide synthase. Proc. Natl. Acad. Sci. U. S. A. 95, 8880-8885.

54. Laufs, U., Gertz, K., Huang, P., Nickenig, G., Bohm, M., Dirnagl, U., and Endres, M. (2000) Atorvastatin upregulates type III nitric oxide synthase in thrombocytes, decreases platelet activation, and protects from cerebral ischemia in normocholesterolemic mice. Stroke 31, 2442-2449.

55. Yamada, M., Huang, Z., Dalkara, T., Endres, M., Laufs, U., Waeber, C., Huang, P.L., Liao, J.K., and Moskowitz, M.A. (2000) Endothelial nitric oxide synthase-dependent cerebral blood flow augmentation by l-arginine after chronic statin treatment. J. Cereb. Blood Flow Metab. 20, 709-717.

56. Ortego, M., Bustos, C., Hernandez-Presa, M.A., Tunon, J., Diaz, C., Hernandez, G., and Egido, J. (1999) Atorvastatin reduces NF- $s \mathrm{~B}$ activation and chemokine expression in vascular smooth muscle cells and mononuclear cells. Atherosclerosis 147, 253-261.

57. Omori, H., Nagashima, H., Tsurumi, Y., Takagi, A., Ishizuka, N., Hagiwara, N., Kawana, M., and Kasanuki, H. (2002) Direct in vivo evidence of a vascular statin: a single dose of cerivastatin rapidly increases vascular endothelial responsiveness in healthy normocholesterolaemic subjects. Br. J. Clin. Pharmacol. 54, 395-399.

58. Tannous, M., Cheung, R., Vignini, A., and Mutus, B. (1999) Atorvastatin increases ecNOS levels in human platelets of hyperlipidemic subjects. Thromb. Haemost. 82, 1390-1394.

59. Yemisci, M., Ay, H., Kocaefe, C., Qui, J., Topalkara, K., Ozgüç, M., Kirazli, S., Ozcebe, O., Moskowitz, M.A., and Dalkara, T. (2008) Statin potentiates human platelet eNOS activity without enhancing eNOS mRNA and protein levels. Cerebrovasc. Dis. 26, 190-198.

60. Montaner, J. (2005) Treatment with statins in the acute phase of ischemic stroke. Expert Rev. Neurother. 5, $211-221$.

61. Stêpieñ, K., Tomaszewski, M., and Czuczwar, S.J. (2005) Neuroprotective properties of statins. Pharmacol. Rep. 57, 561-569.

62. van der Most, P.J., Dolga, A.M., Nijholt, I.M., Luiten, P.G., and Eisel, U.L. (2009) Statins: mechanisms of neuroprotection. Prog. Neurobiol. 88, 64-75.

63. Hebert, L.E., Scherr, P.A., Bienias, J.L., Bennet, D.A., and Evans, D.A. (2003) Alzheimer's disease in the US population: prevalence estimates using the 2000 census. Arch. Neurol. 60, 1119-1122.

64. De Strooper, B. and Annaert, W. (2000) Proteolytic processing and cell biological functions of the amyloid precursor protein. J. Cell Sci. 113, 1857-1870.

65. Haass, C., Schlossmacher, M.G., Hung, A.Y., Vigo-Pelfrey, C., Mellon, A., Ostaszewski, B.L., Lieberburg, I., Koo, E.H., Schenk, D., Teplow, D.B., and Selkoe, D.J. (1992) Amyloid beta-peptide is produced by cultured cells during normal metabolism. Nature 359, 322-325.

66. Thinakaran, G. and Koo, E.H. (2008). Amyloid precursor protein trafficking, processing, and function. J. Biol. Chem. 283, 29615-29619.

67. Weisgraber, K.H. and Mahley, R.W. (1996) Human apolipoprotein E: the Alzheimer's disease connection. FASEB J. 10, 1485-1494.

68. Poirier, J., Davignon, J., Bouthillier, D., Kogan, S., Bertrand, P., and Gauthier, S. (1993) Apolipoprotein E polymorphism and Alzheimer's disease. Lancet 342, 697-699.

69. Corder, E.H., Saunders, A.M., Strittmatter, W.J., Schmechel, D.E., Gaskell, P.C., Small, G.W., Roses, A.D., Haines, J.L., and Pericak-Vance, M.A. (1993) Gene dose of apolipoprotein E type 4 allele and the risk of Alzheimer's disease in late onset families. Science 261, 921-923.

70. Lavados, M., Farias, G., Rothhammer, F., Guillon, M., Mujica, M.C., Maccioni, C., and Maccioni, R.B. (2005) ApoE alleles and tau markers in patients with different levels of cognitive impairment. Arch. Med. Res. 36, 474-479.

71. Sparks, D.L., Connor, D.J., Sabbagh, M.N., Petersen, R.B., Lopez, J., and Browne, P. (2006) Circulating cholesterol levels, apolipoprotein E genotype and dementia severity influence the benefit of atorvastatin treatment in Alzheimer's disease: results of the Alzheimer's Disease Cholesterol-Lowering Treatment (ADCLT) trial. Acta Neurol. Scand. 185, 3-7.

72. Packard, C.J., Westendorp, R.G., Stott, D.J., Caslake, M.J., Murray, H.M., Shepherd, J., Blauw, G.J., Murphy, M.B., Bollen, E.L., Buckley, B.M., Cobbe, S.M., Ford, I., Gaw, A., Hyland, M., Jukema, J.W., Kamper, A.M., Macfarlane, P.W., Jolles, J., Perry, I.J., Sweeney, B.J., and Twomey, C.; Prospective Study of Pravastatin in the Elderly at Risk Group (2007) Association between apolipoprotein E4 and cognitive decline in elderly adults. J. Am. Geriatr. Soc. 55, 1777-1785. 
73. Trompet, S., van Vliet, P., de Craen, A.J., Jolles, J., Buckley, B.M., Murphy, M.B., Ford, I., Macfarlane, P.W., Sattar, N., Packard, C.J., Stott, D.J., Shepherd, J., Bollen, E.L., Blauw, G.J., Jukema, J.W., and Westendorp, R.G. (2009) Pravastatin and cognitive function in the elderly. Results of the PROSPER study. J. Neurol. [Epub ahead of print]

74. Liu, W.W., Todd, S., Coulson, D.T., Irvine, G.B., Passmore, A.P., McGuinness, B., McConville, M., Craig, D., and Johnston, J.A. (2009) A novel reciprocal and biphasic relationship between membrane cholesterol and beta-secretase activity in SH-SY5Y cells and in human platelets. J. Neurochem. 108, 341-349.

75. Ehehalt, R., Keller, P., Haass, C., Thiele, C., and Simons, K. (2003) Amyloidogenic processing of the Alzheimer $\beta-$ amyloid precursor protein depends on lipid rafts. J. Cell Biol. 160, 113-123.

76. Simons, M., Keller, P., De Strooper, B., Beyreuther, K., Dotti, C.G., and Simons, K. (1998) Cholesterol depletion inhibits the generation of beta-amyloid in hippocampal neurons. Proc. Natl. Acad. Sci. U. S. A. 95, 6460-6464.

Wahrle, S., Das, P., Nyborg, A.C., McLendon, C., Shoji, M., Kawarabayashi, T., Younkin, L.H., Younkin, S.G., and Golde, T.E. (2002) Cholesterol-dependent gamma-secretase activity in buoyant cholesterol-rich membrane microdomains. Neurobiol. Dis. 9, 11-23.

78. Grimm, M.O., Grimm, H.S., Tomic, I., Beyreuther, K., Hartmann, T., and Bergmann, C. (2008) Independent inhibition of Alzheimer disease beta- and gamma-secretase cleavage by lowered cholesterol levels. J. Biol. Chem. 283, 11302-11311.

79. Bodovitz, S. and Klein, W.L. (1996) Cholesterol modulates $\alpha$-secretase cleavage of amyloid precursor protein. J. Biol. Chem. 271, 4436-4440.

80. Kojro, E., Gimple, G., Lammich, S., März, W., and Fahrenholz, F. (2001) Low cholesterol stimulates the nonamyloidogenic pathway by its effect on the alpha-secretase ADAM 10. Proc. Natl. Acad. Sci. U. S. A. 98, 58155820 .

81. Fassbender, K., Simons, M., Bergmann, C., Stroick, M., Lutjohann, D., Keller, P., Runz, H., Kuhl, S., Bertsch, T., von Bergmann, K., Hennerici, M., Bevreuther, K., and Hartmann, T. (2001) Simvastatin strongly reduces levels of Alzheimer's disease beta -amyloid peptides Abeta 42 and Abeta 40 in vitro and in vivo. Proc. Natl. Acad. Sci. U. S. A. 98, 5856-5861.

82. Buxbaum, J.D., Cullen, E.I., and Friedhoff, L.T. (2002) Pharmacological concentrations of the HMG-CoA reductase inhibitor lovastatin decrease the formation of the Alzheimer $\beta$-amyloid peptide in vitro and in patients. Front. Biosci. 7, a50-a59.

83. Parvathy, S., Ehrlich, M., Pedrini, S., Diaz, N., Refolo, L., Buxbaum, J.D., Bogush, A., Petanceska, S., and Gandy, S. (2004) Atorvastatin-induced activation of Alzheimer's alpha secretase is resistant to standard inhibitors of protein phosphorylation-regulated ectodomain shedding. J. Neurochem. 90, 1005-1010.

84. Gellermann, G.P., Ullrich, K., Tannert, A., Unger, C., Habicht, G., Sauter, S.R., Hortschansky, P., Horn, U., Mollmann, U., Decker, M., Lehmann, J., and Fandrich, M. (2006) Alzheimer-like plaque formation by human macrophages is reduced by fibrillation inhibitors and lovastatin. J. Mol. Biol. 360, 251-257.

85. Cordle, A. and Landreth, G. (2005) 3-Hydroxy-3-methylglutaryl-coenzyme A reductase inhibitors attenuate betaamyloid-induced microglial inflammatory responses. J. Neurosci. 25, 299-307.

86. Li, L., Cao, D., Garber, D.W., Kim, H., and Fukuchi, K. (2003) Association of aortic atherosclerosis with cerebral beta amyloidosis and learning defects in a mouse model of Alzheimer's disease. Am. J. Pathol. 163, 2155-2164.

87. Refolo, L.M., Malester, B., LaFrancois, J., Bryant-Thomas, T., Wang, R., Tint, G.S., Sambamurthi, K., Duff, K., and Papolla, M.A. (2000) Hypercholesterolemia accelerates the Alzheimer's amyloid pathology in a transgenic mouse model. Neurobiol. Dis. 7, 321-331.

88. Sparks, D.L. (1996) Intraneuronal beta-amyloid immunoreactivity in the CNS. Neurobiol. Aging 17, $291-299$.

89. Tong, X.K., Nicolakakis, N., Fernandes, P., Ongali, B., Brouillette, J., Quirion, R., and Hamel, E. (2009) Simvastatin improves cerebrovascular function and counters soluble amyloid-beta, inflammation and oxidative stress in aged APP mice. Neurobiol. Dis. 35, 406-414.

90. Li, L., Cao, D., Kim, H., Lester, R., and Fukuchi, K. (2006) Simvastatin enhances learning and memory independent of amyloid load in mice. Ann. Neurol. 60, 729-739.

91. Park, I.H., Hwang, E.M., Hong, H.S., Boo, J.H., Oh, S.S., Lee, J., Jung, M.W., Bang, O.Y., Kim, S.U., and MookJung, I. (2003) Lovastatin enhances Abeta production and senile plaque deposition in female $\mathrm{Tg} 2576$ mice. Neurobiol. Aging 24, 637-643.

92. Chauhan, N.B., Siegel, G.J., and Feinstein, D.L. (2004) Effects of lovastatin and pravastatin on amyloid processing and inflammatory response in TgCRND8 brain. Neurochem. Res. 29, 1897-1911.

93. Boimel, M., Grigoriadis, N., Lourbopoulos, A., Touloumi, O., Rosenmann, D., Abramsky, O., and Rosenmann, H. (2009) Statins reduce the neurofibrillary tangle burden in a mouse model of tauopathy. J. Neuropathol. Exp. Neurol. 68, 314-325.

94. Kivipelto, M., Helkala, E.L., Laakso, M.P., Hänninen, T., Hallikainen, M., Alhainen, K., Soininen, H., Tuomilehto, J., and Nissinen, A. (2001) Midlife vascular risk factors and Alzheimer's disease in later life: longitudinal, population based study. BMJ 322, 1447-1451.

95. Notkola, I.L., Sulkava, R., Pekkanen, J., Erkinjuntti, T., Ehnholm. C., Kivinen, P., Tuomilehto, J., and Nissinen, A. (1998) Serum total cholesterol, apolipoprotein E epsilon 4 allele, and Alzheimer's disease. Neuroepidemiology 17, 14-20. 
96. Anstey, K.J., Lipnicki, D.M., and Low, L.F. (2008) Cholesterol as a risk factor for dementia and cognitive decline: a systematic review of prospective studies with meta-analysis. Am. J. Geriatr. Psychiatry 16, 343-354.

97. Launer, L.J., White, L.R., Petrovitch, H., Ross, G.W., and Curb, J.D. (2001) Cholesterol and neuropathologic markers of AD: a population-based autopsy study. Neurology 57, 1447-1452.

98. Kuo, Y.M., Emmerling, M.R., Bisgaier, C.L., Essenburg, A.D., Lampert, H.C., Drumm, D., and Roher, A.E. (1998) Elevated low-density lipoprotein in Alzheimer's disease correlates with brain abeta 1-42 levels. Biochem. Biophys. Res. Commun. 252, 711-715.

99. Tan, Z.S., Seshadri, S., Beiser, A., Wilson, P.W., Kiel, D.P., Tocco, M., D'Agostino, R.B., and Wolf, P.A. (2003) Plasma total cholesterol level as a risk factor for Alzheimer disease. The Framingham study. Arch. Intern. Med. 163, 1053-1057.

100. Li, G., Shofer, J.B., Kukull, W.A., Peskind, E.R., Tsuang, D.W., Breitner, J.C., McCormick, W., Bowen, J.D., Teri, L., Schellenberg, G.D., and Larson, E.B. (2005) Serum cholesterol and risk of Alzheimer's disease. Neurology 65, $1045-1050$.

101. Rockwood, K. (2006) Epidemiological and clinical trials evidence about a preventive role for statins in Alzheimer's disease. Acta Neurol. Scand. Suppl. 185, 71-77.

102. Haag, M.D., Hofman, A., Koudstaal, P.J., Stricker, B.H., and Breteler, M.M. (2009) Statins are associated with a reduced risk of Alzheimer disease regardless of lipophilicity. The Rotterdam Study. J. Neurol. Neurosurg. Psychiatry 80, $13-17$.

103. Sparks, D.L., Kryscio, R.J., Sabbagh, M.N., Connor, D.J., Sparks, L.M., and Liebsack, C. (2008) Reduced risk of incident AD with elective statin use in a clinical trial cohort. Curr. Alzheimer Res. 5, 416-421.

104. Jick, H., Zornberg, G.L., Jick, S.S., Seshadri, S., and Drachman, D.A. (2000) Statins and the risk of dementia. Lancet 356, 1627-1631.

105. Ostrowski, S.M., Wilkinson, B.L., Golde, T.E., and Landreth, G. (2007) Statins reduce amyloid-beta production through inhibition of protein isoprenylation. J. Biol. Chem. 282, 26832-26844.

106. Won, J.S., Im, Y.B., Khan, M., Contreras, M., Singh, A.K., and Singh, I. (2008) Lovastatin inhibits amyloid precursor protein (APP) beta-cleavage through reduction of APP distribution in Lubrol WX extractable low density lipid rafts. J. Neurochem. 105, 1536-1549.

107. Zhou, Y., Suram, A., Venugopal, C., Prakasam, A., Lin, S., Su, Y., Li, B., Paul, S.M., and Sambamurti, K. (2008) Geranylgeranyl pyrophosphate stimulates gamma-secretase to increase the generation of Abeta and APP-CTFgamma. FASEB J. 22, 47-54.

108. Cole, S.L., Grudzien, A., Manhart, I.O., Kelly, B.L., Oakley, H., and Vassar, R. (2005) Statins cause intracellular accumulation of amyloid precursor protein, beta-secretase-cleaved fragments, and amyloid beta-peptide via an isoprenoid-dependent mechanism. J. Biol. Chem. 280, 18755-18770.

109. Pedrini, S., Carter, T.L., Prendergast, G., Petanceska, S., Ehrlich, M.E., and Gandy, S. (2005) Modulation of statinactivated shedding of Alzheimer APP ectodomain by ROCK. PLoS Med. 2, e18.

110. McGuinness, B., Craig, D., Bullock, R., and Passmore, P. (2009) Statins for the prevention of dementia. Cochrane Database Syst. Rev. 2, CD003160.

111. Arvanitakis, Z., Schneider, J.A., Wilson, R.S., Bienias, J.L., Kelly, J.F., Evans, D.A., and Bennett, D.A. (2008) Statins, incident Alzheimer disease, change in cognitive function, and neuropathology. Neurology 70, 1795-1802.

112. Jones, R.W., Kivipelto, M., Feldman, H., Sparks, L., Doody, R., Waters, D.D., Hey-Hadavi, J., Breazna, A., Schindler, R.J., Ramos, H., and LEADe investigators. (2008) The Atorvastatin/Donepezil in Alzheimer's Disease Study (LEADe): design and baseline characteristics. Alzheimers Dement. 4, 145-153.

113. Solomon, A. and Kivipelto, M. (2009) Cholesterol-modifying strategies for Alzheimer's disease. Expert Rev. Neurother. 9, 695-709.

114. Sparks, L. (2009) Statins and cognitive function. J. Neurol. Neurosurg. Psychiatry 80, 1-2.

115. Sparks, D.L., Kivipelto, M., Doody, R., et al. (2008) The Atorvastatin/Donepezil in Alzheimer's Disease (LEADe) study: effect of atorvastatin on Alzheimer's disease progression by ApoE4 genotype. Presented at the Alzheimer's Association International Conference on Alzheimer's Disease. Chicago, IL, USA, 26-31 July (Abstract).

116. Sano, M. (2008) Multi-center, randomized, double-blind, placebo-controlled trial of simvastatin to slow the progression of Alzheimer's disease. Presented at the Alzheimer's Association International Conference on Alzheimer's Disease. Chicago, IL, USA, 26-31 July (Abstract T200).

117. Kearney, D. and Fitzgerald, D. (1999) The antithrombotic effects of statins. J. Am. Coll. Cardiol. 33, $1305-1307$.

118. Undas, A., Brummel, K.E., Musial, J., Mann, K.G., and Szczeklik, A. (2001) Simvastatin depresses blood clotting by inhibiting activation of prothrombin, factor V, and factor XIII and by enhancing factor Va inactivation. Circulation 103, 2248-2253.

119. Undas, A., Celinska-Lowenhoff, M., Brummel-Ziedins, K.E., Brozek, J., Szczeklik, A., and Mann, K.G. (2005) Simvastatin given for 3 days can inhibit thrombin generation and activation of factor $\mathrm{V}$ and enhance factor $\mathrm{Va}$ inactivation in hypercholesterolemic patients. Arterioscler. Thromb. Vasc. Biol. 25, 1524-1525.

120. Lowe, G., Rumley, A., Norrie, J., Ford, I., Shepherd, J., Cobbe, S., Macfarlane, P., and Packard, C. (2000) Blood rheology, cardiovascular risk factors, and cardiovascular disease: the West of Scotland Coronary Prevention Study. Thromb. Haemost. 84, 553-558. 
121. Muravyov, A.V., Yakusevich, V.V., Surovaya, L., and Petrochenko, A. (2004) The effect of simvastatin therapy on hemorheological profile in coronary heart desease (CHD) patients. Clin. Hemorheol. Microcirc. 31, 251-256.

122. Goldstein, L.B., Adams, R., Alberts, M.J., Appel, L.J., Brass, L.M., Bushnell, C.D., Culebras, A., DeGraba, T.J., Gorelick, P.B., Guyton, J.R., Hart, R.G., Howard, G., Kelly-Hayes, M., Nixon, J.V., Sacco, R.L., and American Heart Association; American Stroke Association Stroke Council (2006) Primary prevention of ischemic stroke: a guideline from the American Heart Association/American Stroke Association Stroke Council: cosponsored by the Atherosclerotic Peripheral Vascular Disease Interdisciplinary Working Group; Cardiovascular Nursing Council; Clinical Cardiology Council; Nutrition, Physical Activity, and Metabolism Council; and the Quality of Care and Outcomes Research Interdisciplinary Working Group. Circulation 113, e873-923.

123. Knottnerus, I.L., Ten Cate, H., Lodder, J., Kessels, F., and van Oostenbrugge, R.J. (2009) Endothelial dysfunction in lacunar stroke: a systematic review. Cerebrovasc. Dis. 27, 519-526.

124. Kim, J.S., Lee, H.S., Park, H.Y., Kim, S.S., Kang, H.G., Kim, N.H., Park, J.S., and Kim, Y. (2009) Endothelial function in lacunar infarction: a comparison of lacunar infarction, cerebral atherosclerosis and control group. Cerebrovasc. Dis. 28, 166-170.

125. Arboix, A. and Martí-Vilalta, J.L. (2009) Lacunar stroke. Expert Rev. Neurother. 9, 179-196.

126. Barnett, H.J.M., Mohr, J.P., Stein, B.M., and Yatsu, F.M. (1998) Stroke: Pathophysiology, Diagnosis, and Management. 3rd ed. Churchill Livingstone, New York.

127. Amarenco, P., Bogousslavsky, J., Caplan, L.R., Donnan, G.A., and Hennerici, M.G. (2009) Classification of stroke subtypes. Cerebrovasc. Dis. 27, 493-501.

128. Miyashita, K., Naritomi, H., Nakamura, M., Kazui, S., and Sawada, T. (1991) Old cerebral hemorrhages in cases of multiple lacunar infarction found by magnetic resonance imaging. Cerebrovasc. Dis. 1, 321-326.

129. Roob, G., Lechner, A., Schmidt, R., Flooh, E., Hartung, H.P., and Fazekas, F. (2000) Frequency and location of microbleeds in patients with primary intracerebral hemorrhage. Stroke 31, 2665-2669.

130. Labovitz, D.L., Boden-Albala, B., Hauser, W.A., and Sacco, R.L. (2007) Lacunar infarct or deep intracerebral hemorrhage, who gets which? The Northern Manhattan Study. Neurology 68, 606-608.

131. Anon. (1995) Cholesterol, diastolic blood pressure, and stroke: 13,000 strokes in 450,000 people in 45 prospective cohorts. Prospective studies collaboration. Lancet 346, 1647-1653.

132. Shahar, E., Chambless, L.E., Rosamond, W.D., Boland, L.L., Ballantyne, C.M., McGovern, P.G., and Sharrett, A.R. (2003) Plasma lipid profile and incident ischemic stroke: the Atherosclerosis Risk in Communities (ARIC) study. Stroke 34, 623-631.

133. Kurth, T., Everett, B.M., Buring, J.E., Kase, C.S., Ridker, P.M., and Gaziano, J.M. (2007) Lipid levels and the risk of ischemic stroke in women. Neurology 68, 556-562.

134. Tirschwell, D.L., Smith, N.L., Heckbert, S.R., Lemaitre, R.N., Longstreth, W.T. Jr., and Psaty, B.M. (2004) Association of cholesterol with stroke risk varies in stroke subtypes and patient subgroups. Neurology 63, 1868-1875.

135. Sanossian, N. and Tarlov, N.E. (2008) HDL-C and LDL-C: their role in stroke pathogenesis and implications for treatment. Curr. Treat. Options Cardiovasc. Med. 10, 195-206.

136. Curb, J.D., Abbott, R.D., Rodriguez, B.L., Masaki, K.H., Chen, R., Popper, J.S., Petrovitch, H., Ross, G.W., Schatz, I.J., Belleau, G.C., and Yano, K. (2004) High density lipoprotein cholesterol and the risk of stroke in elderly men: the Honolulu heart program. Am. J. Epidemiol. 160, 150-157.

137. Sacco, R.L., Benson, R.T., Kargman, D.E., Boden-Albala. B., Tuck, C., Lin, I.F., Cheng, J.F., Paik, M.C., Shea, S., and Berglund, L. (2001) High-density lipoprotein cholesterol and ischemic stroke in the elderly: the Northern Manhattan Stroke Study. JAMA 285, 2729-2735.

138. Castelli, W.P., Anderson, K., Wilson, P.W., and Levy, D. (1992) Lipids and risk of coronary heart disease. The Framingham Study. Ann. Epidemiol. 2, 23-28.

139. Bots, M.L., Elwood, P.C., Nikitin, Y., Salonen, J.T., Freire, de Concalves, A., Inzitari, D., Sivenius, J., Benetou, V., Tuomilehto, J., Koudstaal, P.J., and Grobbee, D.E. (2002) Total and HDL cholesterol and risk of stroke. EUROSTROKE: a collaborative study among research centres in Europe. J. Epidemiol. Community Health 56, i19i24.

140. Emond, M.J. and Zareba, W. (1997) Prognostic value of cholesterol in women of different ages. J. Womens Health 6, 295-307.

141. McNeill, A.M., Schmidt, M.I., Rosamond, W.D., East, H.E., Girman, C.J., Ballantyne, C.M., Golden, S.H., and Heiss, G. (2005) The metabolic syndrome and 11-year risk of incident cardiovascular disease in the Atherosclerosis Risk in Communities Study. Diabetes Care 28, 385-390.

142. Iso, H., Jacobs, D.R., Jr., Wentworth, D., Neaton, J.D., and Cohen, J.D. (1989) Serum cholesterol levels and six-year mortality from stroke in 350,977 men screened for the Multiple Risk Factors International Trial. N. Engl. J. Med. 320, 904-910.

143. Sauvaget, C., Nagano, J., Hayashi, M., and Yamada, M. (2004) Animal protein, animal fat, and cholesterol intakes and risk of cerebral infarction mortality in the adult health study. Stroke 35, 1531-1537.

144. Iribarren, C., Jacobs, D.R., Sadler, M., Claxton, A.J., and Sidney, S. (1996) Low total serum cholesterol and intracerebral hemorrhagic stroke: is the association confined to elderly men? The Kaiser Permanente Medical Care Program. Stroke 27, 1993-1998. 
145. Gatchev, O., Rastam, L., Lindberg, G., Gullberg, B., Eklund, G.A., and Isacsson, S.O. (1993) Subarachnoid hemorrhage, cerebral hemorrhage, and serum cholesterol concentration in men and women. Ann. Epidemiol. 3, 403-409.

146. Elkind, M.S., Flint, A.C., Sciacca, R.R., and Sacco, R.L. (2005) Lipid-lowering agent use at ischemic stroke onset is associated with decreased mortality. Neurology. 65, 253-258.

147. Greisenegger, S., Müllner, M., Tentschert, S., Lang, W., and Lalouschek, W. (2004) Effect of pretreatment with statins on the severity of acute ischemic cerebrovascular events. J. Neurol. Sci. 221, 5-10.

148. Almog, Y., Shefer, A., Novack, V., Maimon, N., Barski, L., Eizinger, M., Friger, M., Zeller, L., and Danon, A. (2004) Prior statin therapy is associated with a decreased rate of severe sepsis. Circulation 110, 880-885.

149. Marti-Fabregas, J., Gomis, M., Arboix, A., Aleu, A., Pagonabarraga, J., Belvis, R., Cocho, D., Roquer, J., Rodriguez, A., Garcia, M.D., Molina-Porcel, L., Diaz-Manera, J., and Marti-Vilalta, J.L. (2004) Favorable outcome of ischemic stroke in patients pretreated with statins. Stroke 35, 1117-1121.

150. Gong, C., Hoff, J.T., and Keep, R.F. (2000) Acute inflammatory reaction following experimental intracerebral hemorrhage in rat. Brain Res. 871, 57-65.

151. Jung, K.H., Chu, K., Jeong, S.W., Han, S.Y., Lee, S.T., Kim, J.Y., Kim, M., and Roh, J.K. (2004) HMG-CoA reductase inhibitor, atorvastatin, promotes sensorimotor recovery, suppressing acute inflammatory reaction after experimental intracerebral hemorrhage. Stroke 35, 1744-1749.

152. Endres, M., Laufs, U., Huang, Z., Nakamura, T., Huang, P., Moskowitz, M.A., and Liao, J.K. (1998) Stroke protection by 3-hydroxy-3-methylglutaryl (HMG)-CoA reductase inhibitors mediated by endothelial nitric oxide synthase. Proc. Natl. Acad. Sci. U. S. A. 95, 8880-8885.

153. Vaughan, C.J., Murphy, M.D., and Buckley, B.M. (1996) Statins do more than just lower cholesterol. Lancet 348, 1079-1082.

154. Amarenco, P., Bogousslavsky, J., Callahan, A., III, Goldstein, L.B., Hennerici, M., Rudolph, A.E., Sillesen, H., Simunovic, L., Szarek, M., Welch, K.M., and Zivin, J.A. (2006) High-dose atorvastatin after stroke or transient ischemic attack. N. Engl. J. Med. 355, 549-559.

155. Amarenco, P., Labreuche, J., Lavallee, P., and Touboul, P.J. (2004) Statins in stroke prevention and carotid atherosclerosis: systematic review and up-to-date meta-analysis. Stroke 35, 2902-2909.

156. Leker, R.R., Khoury, S.T., Rafaeli, G., Shwartz, R., Eichel, R., Tanne, D.; on behalf of the NASIS Investigators. (2009) Prior use of statins improves outcome in patients with intracerebral hemorrhage: prospective data from the National Acute Stroke Israeli Surveys (NASIS). Stroke 40, 2581-2584.

157. Byington, R.P., Davis, B.R., Plehn, J.F., White, H.D., Baker, J., Cobbe, S.M., and Shepherd, J. (2001) Reduction of stroke events with pravastatin: the Prospective Pravastatin Pooling (PPP) Project. Circulation 103, 387-392.

158. Kim, B.J., Lee, S.H., Ryu, W.S., Kang, B.S., Kim, C.K., and Yoon, B.W. (2009) Low level of low-density lipoprotein cholesterol increases hemorrhagic transformation in large artery atherothrombosis but not in cardioembolism. Stroke 40, 1627-1632.

159. Woo, D., Kissela, B.M., Khoury, J.C., Sauerbeck, L.R., Haverbusch, M.A., Szaflarski, J.P., Gebel, J.M., Pancioli, A.M., Jauch, E.C., Schneider, A., Kleindorfer, D., and Broderick, J.P. (2004) Hypercholesterolemia, HMG-CoA reductase inhibitors, and risk of intracerebral hemorrhage: a case-control study. Stroke 35, 1360-1364.

160. Ordovas, J.M., Lopez-Miranda, J., Perez-Jimenez, F., Rodriguez, C., Park, J.S., Cole, T., and Schaefer, E.J. (1995) Effects of Apolipoprotein E and A-IV phenotypes on the low-density lipoprotein response to HMG CoA reductase inhibitor therapy. Atherosclerosis 113, 157-166.

161. Feigin, V.L., Rinkel, G.J., Lawes, C.M., Algra, A., Bennett, D.A., van Gijn, J., and Anderson, C.S. (2005) Risk factors for subarachnoid hemorrhage: an updated systematic review of epidemiological studies. Stroke 36, 2773-2780.

162. Teunissen, L., Rinkel, G., Algra, A., and van Gijn, J. (1996) Risk factors for subarachnoid hemorrhage a systematic review. Stroke 27, 544-549.

163. Bang, O.Y., Saver, J.L., Liebeskind, D.S., Starkman, S., Villablanca, P., Salamon, N., Buck, B., Ali, L., Restrepo, L., Vinuela, F., Duckwiler, G., Jahan, R., Razinia, T., and Ovbiagele, B. (2007) Cholesterol level and hemorrhagic transformation after ischemic stroke thrombolysis. Neurology 68, 737-742.

164. Fuentes, B., Martínez-Sánchez, P., and Díez-Tejedor, E. (2009) Lipid-lowering drugs in ischemic stroke prevention and their influence on acute stroke outcome. Cerebrovasc. Dis. 27, 126-133.

165. Bacigaluppi, M. and Hermann, D.M. (2008) New targets of neuroprotection in ischemic stroke. TheScientificWorldJOURNAL 8, 698-712.

166. Blanco, M., Nombela, F., Castellanos, M., Rodriguez-Yanez, M., Garcia-Gil, M., Leira, R., Lizasoain, I., Serena, J., Vivancos, J., Moro, M.A., Dávalos, A., and Castillo, J. (2007) Statin treatment withdrawal in ischemic stroke: a controlled randomized study. Neurology 69, 904-910.

\section{This article should be cited as follows:}

Reiss, A.B. and Wirkowski, E. (2009) Statins in neurological disorders: mechanisms and therapeutic value. TheScientificWorldJOURNAL 9, 1242-1259. DOI 10.1100/tsw.2009.141. 


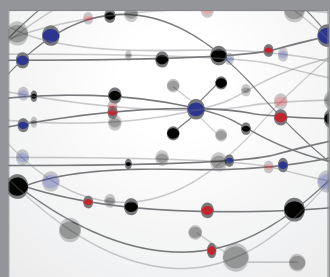

The Scientific World Journal
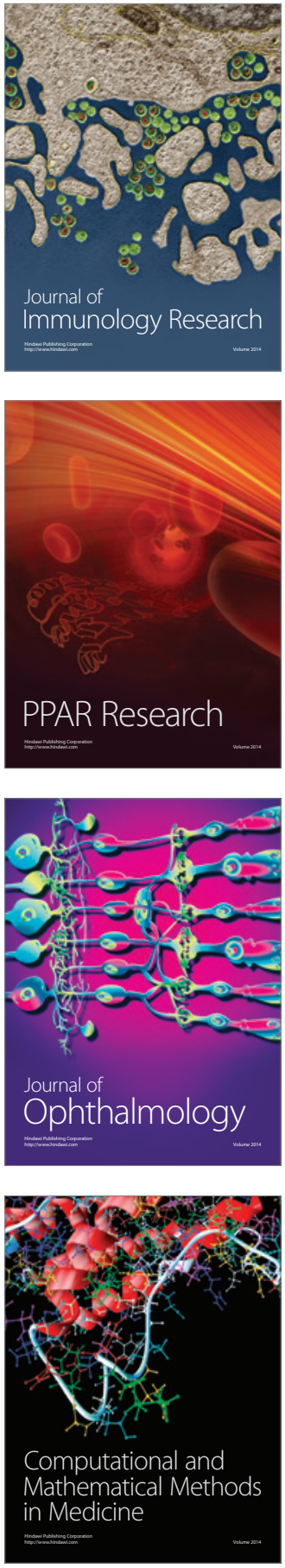

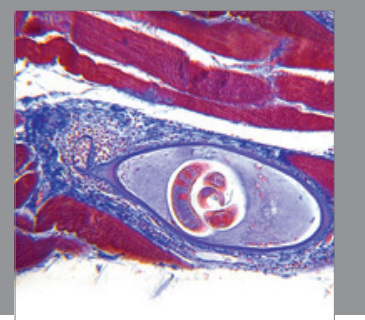

Gastroenterology

Research and Practice
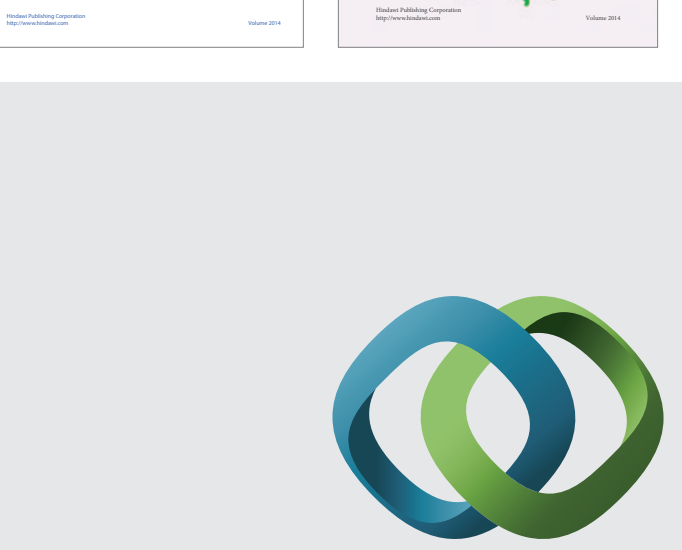

\section{Hindawi}

Submit your manuscripts at

http://www.hindawi.com
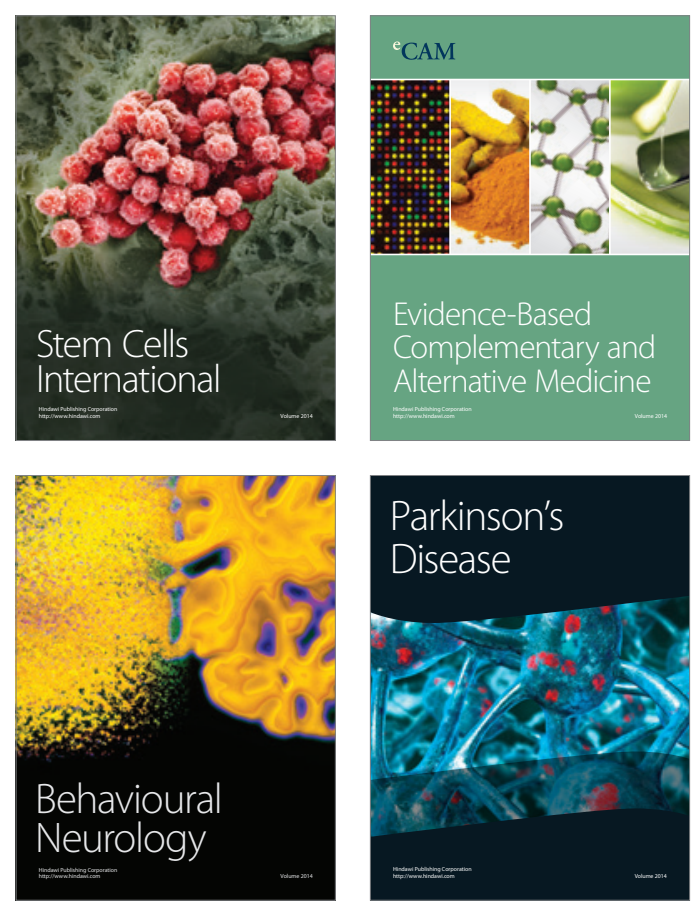

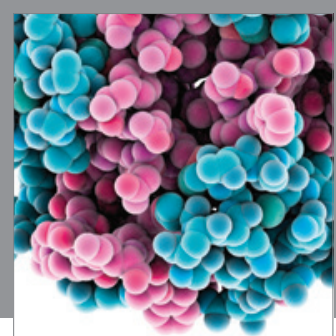

Journal of
Diabetes Research

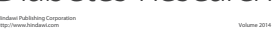

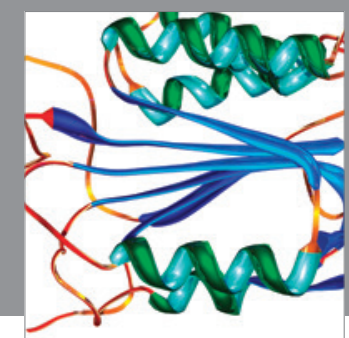

Disease Markers
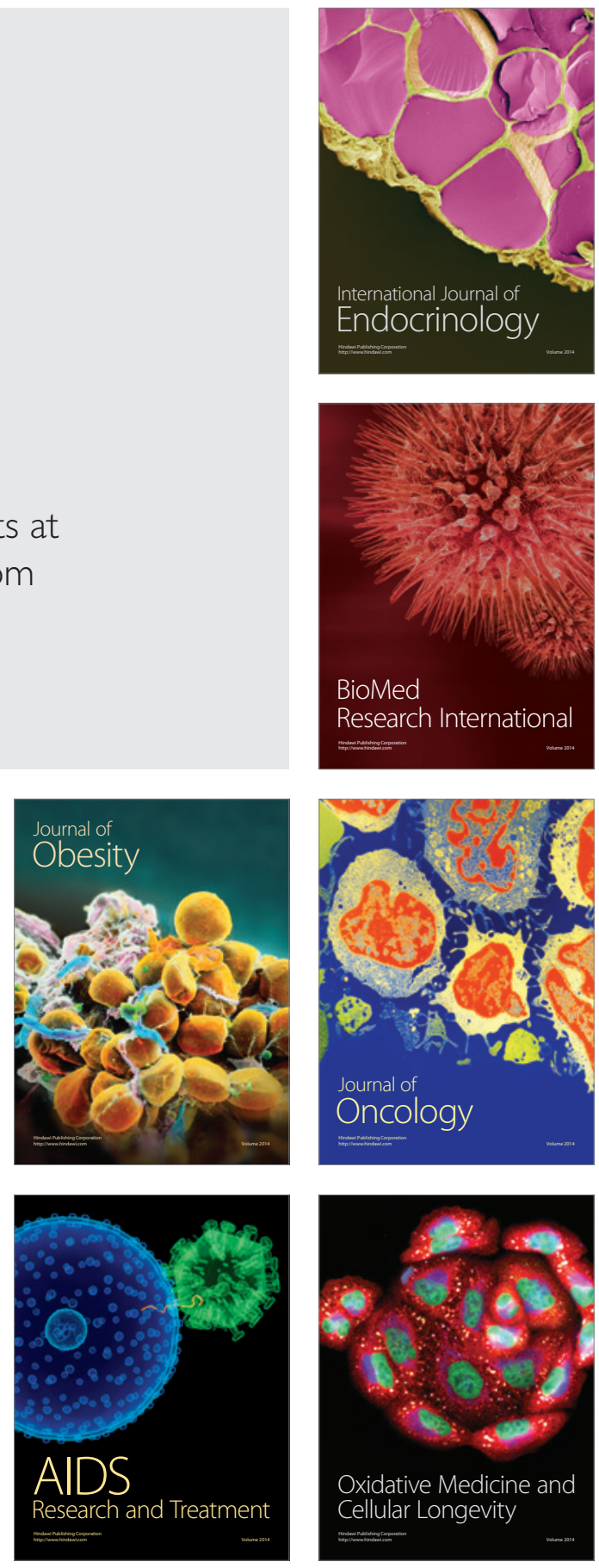